\title{
As dimensões existenciais da precariedade: jovens trabalhadores e os seus modos de vida
}

The Existential Dimensions of Precariousness: Young Workers and Their Ways of Life

Les dimensions existentielles de la précarité: les jeunes travailleurs et leur mode de vie

\section{Renato Miguel do Carmo e Ana Rita Matias}

\section{OpenEdition}

\section{Journals}

Edição electrónica

URL: http://journals.openedition.org/rccs/8502

DOI: $10.4000 /$ rccs.8502

ISSN: 2182-7435

\section{Editora}

Centro de Estudos Sociais da Universidade de Coimbra

Edição impressa

Data de publição: 1 maio 2019

Paginação: 53-78

ISSN: 0254-1106

\section{Refêrencia eletrónica}

Renato Miguel do Carmo e Ana Rita Matias, « As dimensões existenciais da precariedade: jovens trabalhadores e os seus modos de vida », Revista Crítica de Ciências Sociais [Online], 118| 2019, posto online no dia 26 abril 2019, consultado o 19 março 2020. URL : http://journals.openedition.org/rccs/ 8502 ; DOI : https://doi.org/10.4000/rccs.8502 


\title{
RENATO MIGUEL DO CARMO, ANA RITA MATIAS
}

\section{As dimensões existenciais da precariedade: jovens trabalhadores e os seus modos de vida*}

\begin{abstract}
Os jovens são considerados um dos grupos mais afetado pela crise, tornando-se assim mais vulneráveis a condições precárias de trabalho. Este artigo procura compreender os impactos sociais e individuais da precariedade no seu modo de vida, a partir da análise de um conjunto variado de dimensões objetivas e subjetivas, que refletem as perceções dos indivíduos sobre os seus percursos no presente e no futuro. Realizaram-se entrevistas semidiretivas a 24 jovens portugueses licenciados. Uma das principais conclusões indica que o futuro tende a ser encarado com grande imprevisibilidade e incerteza, o que afeta não só a sua condição económica, como também o seu modo de vida. Na verdade, para a maioria dos entrevistados a experiência profissional atual incorpora alguns aspetos considerados alienantes, que restringem a capacidade de autonomia e de agência por parte do sujeito.
\end{abstract}

Palavras-chave: condições de vida; contrato de trabalho; juventude; mercado de trabalho; precariedade laboral.

\section{Introdução}

A participação dos jovens no mercado de trabalho tem sido alvo de um crescente interesse pela academia e organizações internacionais (Carmo e Matias, 2019; OECD, 2016; Comissão Europeia, 2016; Ferreira et al., 2017; Carmo et al., 2014). ${ }^{1}$ A persistência de níveis elevados de desemprego e inatividade entre os indivíduos na faixa etária dos 15 aos 29 anos (alguns estudos estendem esta faixa até aos 35 anos) fez emergir preocupações sobre as suas consequências ao nível da coesão das sociedades, nomeadamente pelo

\footnotetext{
* Este artigo insere-se nas atividades desenvolvidas no âmbito do projeto "Opening Futures: Young People's Vulnerabilities and Social Cohesion Policies”, financiado pela Fundação para a Ciência e a Tecnologia $(\mathrm{IF} / 00053 / 2013)$.

1 Ao longo deste artigo utilizamos a noção de "mercado de trabalho" no sentido mais amplo em que esta é recorrentemente explicitada. De qualquer modo, entendemos que esta noção apresenta ambiguidades consideráveis resultantes do modo como é social e politicamente produzida e contruída, como tem sido demonstrado, pelo menos desde as análises percursoras de Karl Polanyi (1944) sobre a questão da mercantilização do trabalho no contexto da economia capitalista.
} 
facto de esta ser a geração com os níveis mais elevados de escolaridade e de formação na história de muitos países. Ademais, os jovens são considerados um dos grupos mais afetados pela Grande Recessão; como tal, podem estar mais predispostos a aceitar contratos de trabalho precários num contexto de maior flexibilização dos contratos de trabalho - isto é, formas atípicas de contratos de trabalho, geralmente associados a baixos salários - do que qualquer outro segmento etário da população (OECD, 2016). As condições precárias de trabalho afetam uma dimensão objetiva da vida dos jovens (permanência em situações contratuais atípicas, com benefícios sociais limitados, insegurança profissional e com baixos salários, entre outros); mas também uma dimensão subjetiva (associada às consequências que a instabilidade e os riscos imprevisíveis relativos à precariedade têm na definição de planos de vida e de futuro) (Bartolini et al., 2015; Bove et al., 2017).

Este artigo discute os impactos da precariedade na vida dos indivíduos, para além da esfera estritamente profissional, a partir dos resultados de um estudo qualitativo no âmbito do qual se realizaram entrevistas semidiretivas a uma amostra não probabilística de 24 jovens em situações de precariedade profissional (designadamente, estágios remunerados/não remunerados, bolsas de investigação, contratos a termo, recibos verdes, a trabalhar de modo informal, desempregados). Os jovens entrevistados, com idades balizadas entre os 22 e 32 anos, possuíam formação superior em diferentes áreas científicas, viviam na Área Metropolitana de Lisboa e foram selecionados a partir da técnica designada por "bola de neve". Nas entrevistas realizadas, mapearam-se as trajetórias profissionais desde que os jovens ingressaram no ensino superior até ao momento em que se encontravam no mercado de trabalho, focando quatro grandes dimensões: a) percurso e representações do ensino superior; b) condição e percurso laboral; c) quotidiano e transições (subdivididas em questões sobre a sua autonomia financeira, perceções de justiça, cidadania e participação social); d) projeções do futuro e alternativas. ${ }^{2}$

Esta investigação enquadra-se nas atividades do Observatório das Desigualdades e retoma algumas das dimensões sociológicas de um projeto anterior que são aqui operacionalizadas. ${ }^{3}$ De qualquer forma, o presente estudo diferencia-se em termos de amostra, na medida em que as entrevistas

\footnotetext{
${ }^{2}$ Para uma análise mais desenvolvida e aprofundada deste estudo, cf. Carmo e Matias (2019).

3 Projeto intitulado "Estudo exploratório qualitativo sobre os jovens trabalhadores inseridos em trabalhos pouco qualificados", coordenado por Nuno Alves (ISCTE-IUL) e desenvolvido no âmbito do Observatório das Desigualdades (2010). Realizaram-se 80 entrevistas a jovens, com diferentes níveis de escolaridade, residentes da Área Metropolitana de Lisboa e do Porto e também no concelho de Guimarães.
} 
aplicadas se circunscreveram aos jovens com escolaridade superior. Este dado não significa que a precariedade incida de forma mais acentuada neste grupo. $\mathrm{Na}$ verdade, esta é tendencialmente transversal à população trabalhadora mais jovem, independentemente do seu nível de escolaridade (Alves et al., 2012). Todavia considerámos que seria pertinente identificar de forma mais pormenorizada o modo como a precariedade afeta diferentes dimensões da vida profissional e social entre jovens que mobilizam a formação superior como recurso fundamental de inserção no mercado de trabalho e tendo como pano de fundo uma conjuntura temporal ainda marcada pelos impactos da crise económico-financeira.

Trata-se de um estudo compreensivo, a partir do qual se elaborou uma análise de conteúdo das entrevistas tendo como principais eixos analíticos a identificação das dimensões nucleares que caracterizam a situação social resultante da precariedade laboral. A análise baseou-se assim nos testemunhos recolhidos através das entrevistas aprofundadas por intermédio de uma análise de conteúdo para a qual se utilizou o programa informático de análise de dados qualitativos MAXQDA. ${ }^{4}$

Depois de apresentar o enquadramento teórico em torno das dimensões laborais, socioeconómicas e existenciais da precariedade, o artigo revela na secção seguinte uma das principais conclusões das entrevistas realizadas: apesar de se tratar de percursos profissionais ainda curtos, é já possível constatar a existência de uma multiplicidade de situações contratuais. A entrada destes jovens no mercado de trabalho acontece através de trabalhos precários, que se perpetuam, independentemente do tipo de atividade desenvolvida. Seguidamente, explora-se a ideia de um modo de vida precário, resultante da incerteza profissional e dos baixos rendimentos auferidos, assim como do seu efeito naquilo que é o dia a dia dos jovens e da sua capacidade para traçar projetos de vida. Conclui-se que, do ponto de vista económico-financeiro, a precariedade representa uma situação de semiautonomia que se pode perpetuar ao longo de anos, independentemente de se viver fora da casa dos pais. Por fim, na última parte apresenta-se uma dimensão geralmente mais invisível da precariedade: o seu impacto no bem-estar mental e na qualidade de vida do indivíduo, e na forma como este pensa o seu papel presente e futuro tanto no mundo do trabalho, como na sociedade em geral.

\section{Enquadramento teórico: as dimensões da precariedade}

As evoluções que permitiram a globalização e a desregulamentação e interpenetração dos mercados resultaram numa mudança significativa na forma

${ }^{4}$ Os nomes que identificam os entrevistados são fictícios. 
como as empresas operam, tornando os trabalhadores mais vulneráveis aos efeitos da competição interna e externa e, consequentemente, sujeitos a contínuos ajustamentos e flexibilidades que intensificaram os processos de polarização social e de classe (Carmo et al., 2015; Carmo e Cantante, 2015; Leite et al., 2013; Standing, 2011; Wright, 1997). A duração dos contratos reduziu consideravelmente, de tal forma que a noção de emprego para toda a vida numa determinada empresa ou organização se perdeu quase por completo (Sennett, 1998). A este respeito as iniciativas de desregulamentação realizadas em Espanha, Itália e Grécia, sobretudo após 2008, basearam-se na ideia de aumento da flexibilidade e flexisegurança e não contribuíram para gerar mais emprego, nem foram capazes de promover estabilidade nos postos de trabalho existentes (Gialis e Leontidou, 2016). Pelo contrário, fizeram aumentar a fragmentação do mercado de trabalho, aprofundando assimetrias regionais, sem melhorar os níveis já reduzidos de segurança contratual. Na verdade, o mercado de trabalho para os jovens é cada vez mais caracterizado pela heterogeneidade e por situações contraditórias, em que os segmentos mais qualificados podem coexistir na mesma situação profissional com segmentos menos qualificados (ILO, 2015). Relatórios recentes publicados pela OIT e OCDE revelam uma mudança profunda no modelo de emprego standard e com direitos laborais para o aumento continuado do uso de trabalho precário e sem direitos garantidos (ILO, 2015; OECD, 2016).

Considerando as estruturas e a regulamentação do mercado de trabalho, a precariedade tem sido uma questão muito difícil de apreender, tanto concetualmente, como em termos estatísticos (Kretsos, 2010). Do ponto de vista concetual, a dificuldade reside da natureza diversa do problema: a precariedade relaciona-se com a instabilidade e a insegurança contratual, assim como contratos temporários ou a tempo parcial involuntários, e com salários baixos e profissões pouco qualificadas. O trabalho precário encontra-se, igualmente, relacionado com a falta de controlo sobre as condições de trabalho, a dificuldade de enquadramento e de ação por parte das organizações sindicais e a debilidade dos direitos e dos esquemas de proteção social (Estanque, 2014; Costa et al., 2014). É cada vez mais recorrente que situações de desemprego (às vezes de longa duração) sejam entrelaçadas com as descontinuidades causadas pelo recurso ao trabalho temporário e precário (O'Reilly et al., 2015). Contudo, a condição vulnerável da precariedade também pode contaminar outras dimensões da vida, além da inserção profissional, em particular a incapacidade de fazer face às despesas e a dificuldade de fazer projetos de vida ou de formular planos a médio ou longo prazo. 
No contexto europeu, a crise no emprego jovem ganhou maior expressão em países que passaram por duros ajustamentos económico-financeiros e medidas de austeridade, como Portugal, Grécia, Espanha e Itália. Em Portugal, nos anos em que a crise foi mais profunda, a taxa de emprego jovem atingiu os valores mais baixos da última década (23\%, em 2012, e $21,7 \%$, em 2013). Verificaram-se, igualmente neste período, os valores mais altos na taxa de desemprego jovem - em 2013, 38,1\% dos indivíduos entre os 15 e os 24 anos encontravam-se desempregados (Figura 1). Os dados mais recentes revelam uma melhoria nos dois indicadores.

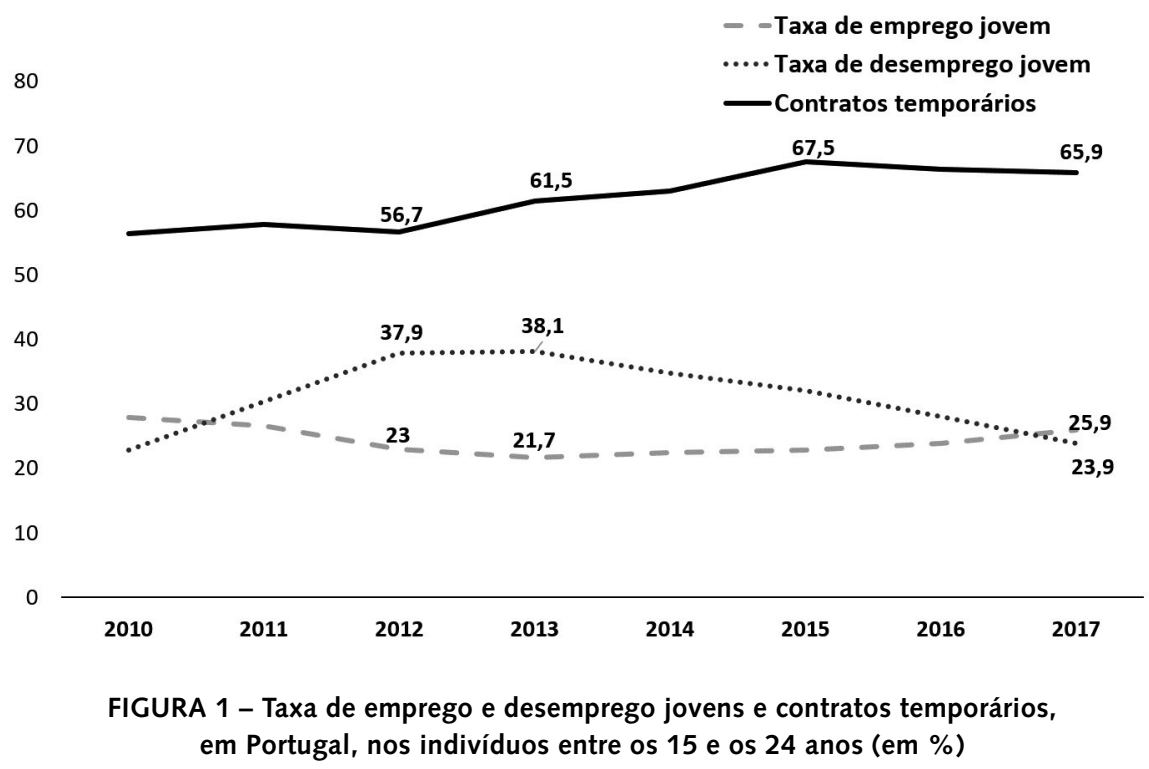

Fonte: Labour Force Survey (EU LFS), Eurostat.

Através da Figura 1 podemos observar que em 2015 se atingiu um pico no que respeita a jovens com contratos temporários $(67,5 \%)$, valor que nos últimos dois anos diminuiu em 1,6 pontos percentuais (65,9\%, em 2017). $\mathrm{Na}$ União Europeia, Portugal faz parte do grupo de países onde existem mais jovens a trabalhar de forma temporária, por não terem encontrado alternativa (Figura 2). Em 2017, 68,3\% dos jovens portugueses, no segmento etário dos 15-24 anos, estariam em trabalho temporário involuntário, ficando muito acima da média europeia $(31,7 \%)$. De registar, porém, a melhoria face ao valor de 2016 (71,1\%) (EU LFS, Eurostat). 


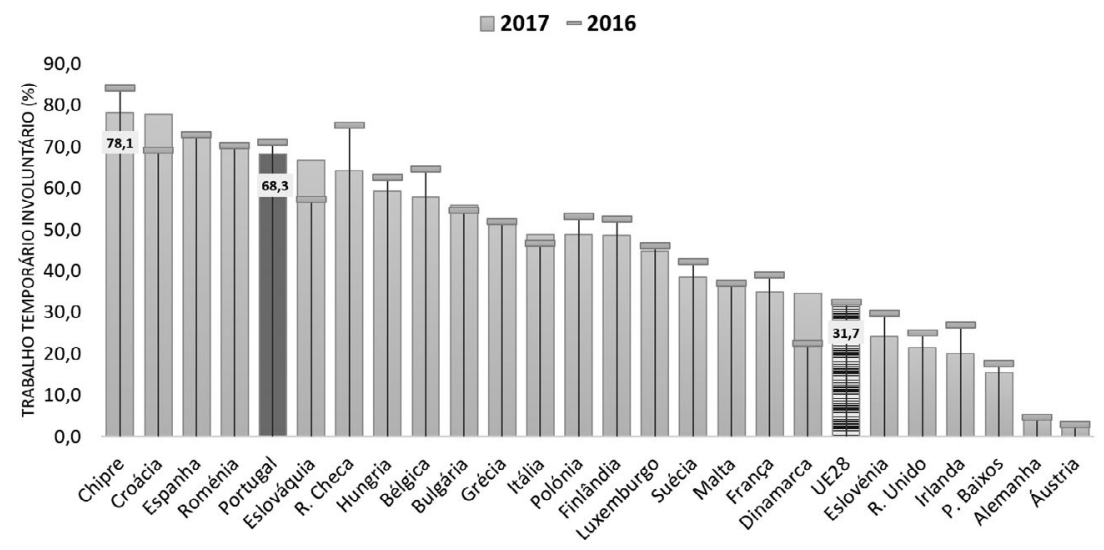

FIGURA 2 - Trabalho temporário involuntário, no segmento etário dos 15-24 anos, na União Europeia, entre 2016 e 2017

Fonte: Labour Force Survey (EU LFS), Eurostat.

Nota: Trabalho temporário involuntário - inquiridos cuja razão para estarem em contratos temporários é o facto de não terem conseguido encontrar um posto permanente (Labour Force Survey).

Num contexto de reduzida oferta de emprego, redução dos subsídios de proteção social e do nível de rendimento disponível dos agregados familiares, os jovens destes países ficaram numa situação de maior vulnerabilidade. Verifica-se, por outro lado, que o brain drain e a perda de trabalhadores com altas qualificações são considerados uma das consequências mais prejudiciais da crise nestes países (Bartolini et al., 2015: 36). A combinação de variáveis como a falta de oportunidades no mercado de trabalho, o aumento da competitividade, o aumento de trabalho com mais insegurança contratual e baixos salários, contribuiu, segundo autores como Ulrich Beck e Elisabeth Beck-Gernsheim (2002), para o aumento de narrativas sobre a responsabilidade individual (materializada, por exemplo, na ideia do empreendedorismo), que começou a ser incorporado no discurso público e tem vindo em grande parte a contribuir para uma tendência de suposta normalização da precariedade. Desta forma, o modelo tradicional, de relações de trabalho standard, que pressupunha um contrato fixo, a tempo inteiro, um salário e uma relação direta com o empregador, é cada vez menos representativo do mercado de trabalho atual (ILO, 2015: 57).

A crescente insegurança fruto da precariedade contratual nas gerações mais jovens converge, naturalmente, nas dimensões de caráter mais 
existencial das suas trajetórias individuais. A imprevisibilidade e a insegurança a que estão sujeitos significam que, embora existam oportunidades de trabalho regular, os salários relativamente baixos não permitem, em muitos casos, alcançar as diferentes etapas que marcam a transição para a vida adulta e a vida ativa, como a saída de casa dos pais, o casamento, a parentalidade e a inserção no mercado de trabalho (Cairns et al., 2014; McDonald et al., 2011). A passagem pela vida deixa de assumir uma trajetória, neste sentido, tão "linear", para passar a ser eventualmente reversível, sincronizada ou adiada (Bynner, 2005; Furlong e Cartmel, 1997; Bradley e Devadason, 2008; Nico, 2014). Face à insegurança generalizada, torna-se mais difícil definir perspetivas de futuro baseadas em escolhas e capacidade de agência, como em expetativas individuais e coletivas, investimentos e estratégias (Atkinson, 2013; Leccardi, 2005).

A este respeito é importante frisar que o significado do conceito de geração e, na relação com este o de juventude ou de jovens, tem merecido da parte das ciências sociais, e particularmente da sociologia, um profícuo e intenso debate científico. Embora neste artigo se tenha optado por não utilizar categorias geracionais que supostamente identificam uma dada coorte etária associada a um certo contexto histórico marcado por processos socioeconómicos e políticos específicos e diferenciadores, convém sublinhar que determinado tipo de marcadores geracionais, como o de geração milénio, estão longe de identificar realidades que se caracterizam pela heterogeneidade social (Ferreira et al., 2017). Na verdade, como muitos autores têm salientado, desde os anos de 1990 a categoria "juventude" (ou "jovem") enquadra necessariamente dinâmicas sociais e processuais não lineares e marcadamente heterogéneas, designadamente na diversidade dos seus modos de vida e das suas práticas culturais (Pais, 1993; Simões, 1999).

Este caráter multidimensional dos estudos da juventude nas interseções com diferentes aspetos e setores da vida social parece-nos ser também a perspetiva sociológica adequada para analisar a que ponto as características da precariedade, anteriormente identificadas, nos remetem para dimensões mais existenciais ligadas às esferas da vida pessoal e social dos indivíduos. A partir dos testemunhos recolhidos pelas entrevistas a jovens trabalhadores, procurar-se-á estudar a influência das situações de precariedade num conjunto diferenciado de dimensões das suas vidas. O esforço analítico de captar os aspetos mais subjetivos e até biográficos que se relacionam com uma experiência continuada de precariedade laboral não só não é fácil de concretizar, como requer necessariamente a condução de análises qualitativas assentes, nomeadamente, em entrevistas aprofundadas. Trata-se de uma linha de investigação ainda muito exploratória, mas que tem sido 
encetada por diversos investigadores em contextos geográficos diferenciados (Mrozowicki, 2016; Kesisoglou et al., 2015).

\section{Caracterização dos percursos de precariedade: fragmentação e perma- nência}

As entrevistas realizadas permitiram evidenciar um quadro de grande diversidade de situações contratuais nos percursos profissionais, como demonstra a Figura 3. Apesar de se estar perante percursos profissionais ainda curtos, estes evidenciam, por um lado, uma enorme fragmentação e descontinuidade e, por outro lado, uma assinalável diversidade e heterogeneidade nas situações contratuais. Contudo, por intermédio da análise pormenorizada destes percursos, foi possível identificar um conjunto relativamente restrito de situações contratuais que ocorrem de forma mais frequente e regular, a saber: contratos a termo, trabalhador por conta de outrem a tempo completo e/ou parcial; bolsa de investigação a tempo completo; recibos verdes, prestação de serviços a tempo parcial; estágios do Instituto do Emprego e Formação Profissional (IEFP) a tempo completo. ${ }^{5}$

Para a maioria destes jovens, a relação existente com a entidade patronal classificava-se como de tempo limitado e temporário, mesmo tratando-se de trabalhos a tempo completo (pelo menos oito horas) ou parcial (até cinco horas). A entrada no mercado de trabalho acontece através de trabalhos precários, que se perpetuam, independentemente do tipo de trabalho ou atividade. As situações de maior precariedade contratual encontram-se precisamente junto daqueles jovens que não desempenham trabalhos relacionados com a área de formação ( 9 em 24 jovens) - o que na maioria

\footnotetext{
${ }^{5}$ Apresenta-se um pequeno glossário sobre as várias modalidades contratuais mais recorrentes: contrato a termo - está expressa no contrato escrito a estipulação do prazo de duração do contrato e a indicação do seu termo (INE); trabalhadores por conta de outrem - indivíduos que exercem uma atividade sob a autoridade e direção de outrem (INE); trabalho temporário - segundo o Eurostat, a noção de trabalho temporário (temporary employment) consiste num acordo entre empregador e trabalhador onde se pressupõe que o fim do trabalho é determinado por condições objetivas, tais como uma data específica, a conclusão de uma tarefa ou o regresso de um trabalhador que foi temporariamente substituído. Exemplos: a) emprego sazonal; b) pessoas recrutadas por uma agência ou uma bolsa de emprego e contratadas por uma entidade terceira para o cumprimento de uma tarefa específica; c) contratos de formação específicos. O Código do Trabalho (artigo 172. ${ }^{\circ}$ ) enquadra o regime de trabalho temporário segundo uma definição mais restrita, que basicamente caracteriza diversas situações de outsourcing identificadas na anterior alínea b (cf. Carmo e Matias, 2019: 37-38); trabalho a tempo parcial - aquele em que o período de trabalho tem uma duração inferior à duração normal de trabalho em vigor na empresa/instituição e que se baseia geralmente numa resposta espontânea do inquirido (INE/ Eurostat); estágios IEFP - estágios com a duração de nove meses, não prorrogáveis, com comparticipação financeira pelo Instituto do Emprego e Formação Profissional (IEFP); trabalho informal - considerou-se como informal o trabalho que não tinha vínculo registado, mas que poderia envolver remuneração (que geralmente não era fixa).
} 

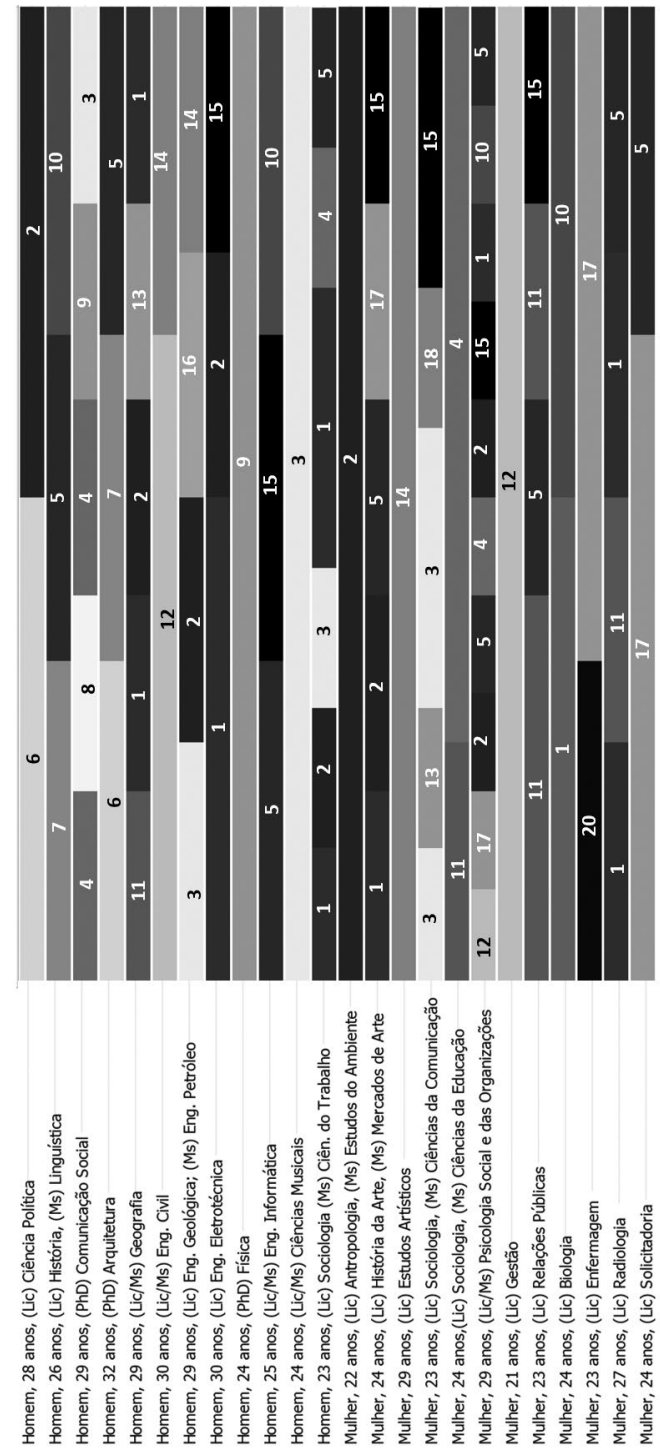
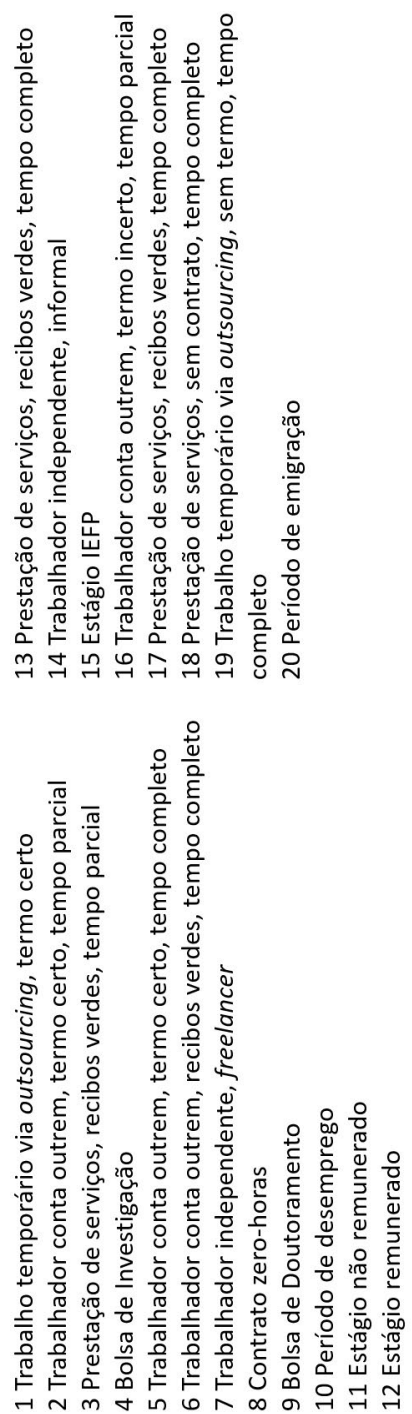

\section{FIGURA 3 - Percursos profissionais segundo a ordem cronológica de entrada no mercado de trabalho}

Fonte: Elaboração dos autores. Resultado produzido pela análise em MAXQDA.

Nota: Esta figura resulta de um exercício exploratório de reconstituição dos percursos profissionais dos entrevistados a partir dos seus testemunhos. Detém, por isso, um estatuto analítico meramente ilustrativo sobre o nível de segmentação dos trajetos em causa. 
dos casos significa trabalhar em cargos administrativos, técnicos ou pouco qualificados (trabalhos por conta de outrem, contrato com termo) ou trabalhar de forma independente, a receber por via informal. Os 13 jovens entrevistados que se encontravam a desempenhar funções relacionadas com a sua área de formação (licenciatura, mestrado ou doutoramento), estavam, na sua maioria, em contexto de estágio (cinco). Os restantes ou estavam a trabalhar por conta de outrem/a termo certo ou faziam prestações de serviço a recibos verdes.

A descrição feita sobre as diferentes modalidades contratuais destes entrevistados revela que todos estes se deparam, de uma forma ou de outra, perante contextos de incerteza profissional. Porém, isto não significa que estejamos, na globalidade, perante trajetórias de precariedade com intensidades e graus de persistência similares - as razões são óbvias: trata-se de uma amostra de indivíduos na qual a maioria das idades se situa abaixo dos 30 anos, com poucas experiências profissionais acumuladas (duas delas tratando-se mesmo da primeira experiência) e no caso de seis dos entrevistados, ainda a terminar a sua formação (mestrado ou doutoramento). Feita a ressalva, apresenta-se a seguir um caso que ilustra um dos maiores riscos associados à precariedade: a sua persistência.

Raquel (29 anos, mestrado em Psicologia) iniciou o seu percurso profissional no âmbito de um programa de estágio remunerado numa câmara municipal, sendo mais tarde integrada num projeto da câmara enquanto técnica superior (com uma remuneração de cerca de $1000 €$ ). Porém, após oito meses, o projeto acabou por ser suspenso e Raquel ficou desempregada. Ao enfrentar a dificuldade em encontrar trabalho na sua área, trabalhou durante um ano num backoffice de uma empresa de telecomunicações (recebendo à volta de $600 €$ ) e posteriormente trabalhou durante três meses, a tempo parcial, num balcão de serviço de apoio ao cliente (auferindo $400 €)$. Entre estes dois trabalhos aceitou uma bolsa de investigação de seis meses, que a obrigou a deslocar-se para o Norte do país (recebia $980 €$ ). Entretanto, candidatou-se a um estágio do IEFP na área de recursos humanos numa multinacional, em Lisboa (com a duração de nove meses): "Depois de ter entrado percebi que estavam em processo de despedimento coletivo, tinham despedido cerca de 300 pessoas. Eu percebi isto vai ser temporário"”. Raquel ficou um mês à procura de emprego e no momento da entrevista estava já há um mês em outra multinacional, num departamento de formação e desenvolvimento, onde ocupava o cargo outrora pertencente a duas pessoas que já não trabalhavam na empresa.

O caso descrito é ilustrativo das situações mais persistentes de precariedade, onde os indivíduos circulam por vários tipos de trabalho e de atividade 
fazendo com que a condição de temporário se transforme num estado percecionado como permanente. Este facto é gerador de desapontamento, desmotivação e angústia. Desde que entram no mercado de trabalho estes jovens passam de uma situação a prazo para outra, ingressando nas mais variadas formas e modalidades contratuais (com ou sem remuneração). Do estágio profissional não remunerado ao estágio do IEFP, do contrato a termo certo na empresa $\mathrm{x}$ a outro na empresa $\mathrm{y}$, de bolsa de investigação a bolsa de doutoramento... tornam-se infindáveis estes trajetos de precariedade que, em muitos casos, são interrompidos por períodos em que não surge nada, o que não é sinónimo de períodos vazios em que não se faz nada. Pelo contrário, estes interregnos, que podem ser de dias ou de meses, são passados a procurar trabalho, consultando anúncios e enviando currículos. Este estado em que o temporário acaba por ser percecionado como permanente tem efeitos muito perniciosos que, como iremos ver, afeta a vida do indivíduo no seu todo.

\subsection{O papel abusivo do recurso aos estágios}

A precariedade contratual não significa a ausência de aquisição de experiências, novas competências e contactos. O problema encontra-se quando esta se torna um dos principais veículos de entrada e permanência no mercado de trabalho. É esta a característica perversa encontrada na precariedade hoje em dia, a sua necessidade, face à falta de alternativas. Neste contexto, o tipo de contrato pode ficar, por vezes, em segundo plano e coloca-se a hipótese de trabalhar em contratos precários se existir uma oportunidade de exercer atividades que estejam ligadas à formação de origem. A precariedade é, neste sentido, percecionada como um mal necessário e troca-se a segurança no presente por experiências, associadas à necessidade de começar a construção de um currículo. No entanto, embora se confrontem com dificuldades do mercado de trabalho - e estas sejam motivo de desilusão e frustração, os jovens continuam a atribuir muita importância à formação superior (não demonstrando arrependimentos a esse nível). Existiram, contudo, alguns jovens que deram conta de que dada a possibilidade de regressar atrás fariam uma escolha mais instrumental, procurando uma formação numa área que consideram ter mais saídas profissionais ou, noutros casos, uma escolha mais vocacional, selecionando um curso relacionado com as aptidões pessoais (independentemente das perspetivas de saída profissional).

No conjunto das situações profissionais identificadas, os estágios merecem particular atenção devido à recorrência com que surgem nos trajetos dos jovens (não por vontade pessoal, mas por não terem encontrado alternativa). Existem e proliferam várias tipologias de estágios em função do seu estatuto 
contratual ou remuneratório (estágios curriculares e em formação, estágios profissionais, estágios com ou sem remuneração, estágio financiados pelo IEFP ou financiados pelas empresas ou outras entidades). Contudo, são os designados estágios do IEFP (ver glossário, nota de rodapé n. ${ }^{\circ} 5$ ) os que se generalizaram e tornaram uma prática comum, à qual muitas empresas e instituições têm recorrido. Estes resultam de candidaturas de empresas ou outras entidades sem fins lucrativos e são financiados na sua quase totalidade por fundos públicos. Trata-se de uma medida enquadrada na Garantia Jovem, que se insere em esquemas de apoio ao emprego com a chancela do programa Portugal 2020, implementado desde 2014 em resposta ao expressivo aumento do desemprego jovem. É interessante perceber como alguns destes jovens percecionam os efeitos perversos e sistémicos associados à generalização deste tipo de estágios, quer ao nível do mercado de trabalho, na sua aceção comum, quer na trajetória profissional do próprio indivíduo.

Porque acho que tive aquele tipo de atitudes que vicia o mercado... eu já fiz três estágios não remunerados! Este foi o terceiro. [...] agora o meu maior receio com o mercado é esse, quando começas parece que nunca tens formação suficiente para teres um contrato normal de trabalho... ou é um estágio do IEFP, ou é uma medida primeiro emprego, ou é um estágio não remunerado de 3 ou 6 meses, há sempre uma artimanha qualquer [...] O meu receio aqui é exatamente esse, se o meu IEFP acabar, eu vou voltar para o mercado de trabalho, fazer o quê?! Vou outra vez estagiar, não remunerado?! (Sílvia, 23 anos, licenciada em Relações Públicas, estágio IEFP)

Em muitos dos relatos sobre as experiências de estágio identificaram-se três tendências atuais relativas a esta modalidade de trabalho, que se relacionam parcialmente: a primeira, a de que existe uma desproporção entre aquilo que é suposto ser o papel de estagiário e o nível de funções asseguradas que lhe são atribuídas, as quais visam suprir necessidades de mão de obra "regular" dentro das empresas; a segunda, a de que de fazer um estágio não advém qualquer certeza de que se ficará na empresa, significando pelo contrário uma situação quase sempre provisória; a terceira, a de que a autonomia e responsabilidade individual perante o trabalho é limitada, levando a que parte considerável das tarefas sejam altamente padronizadas.

[...] às vezes sinto-me ali um bocadinho máquina a trabalhar. Sinto também que sendo estagiária [...] é óbvio que a minha opinião não interessa e sinto que por eu ser estagiária, é como se... eu sinto-me diminuída [...] não me perguntam a minha opinião... [...] às vezes lá sinto-me intimidada. (Amália, 21 anos, licenciada em Gestão, estagiária) 
Tendo em conta os testemunhos apresentados, podemos concluir que um dos problemas associados à precariedade é a sua recursividade: esta perpetua-se independentemente do trabalho que se encontre e da atividade que se desenvolva. A este respeito verificámos que a participação regular em estágios profissionais, por parte destes jovens, acaba por ter um papel decisivo na constituição dessa recursividade.

\subsection{O risco da normalização da precariedade $e$ as expetativas de um bom emprego}

No plano das expetativas para um futuro a curto prazo, parece existir uma certa interiorização de que o percurso profissional sempre se pautará por alguma incerteza e baixos rendimentos (pelo menos no início de "carreira"). As expetativas dos jovens são assim concentradas no curto e médio prazo, num misto de otimismo e incerteza, podendo surgir em simultâneo no discurso de um mesmo indivíduo. A saída de situações de precariedade dependerá tanto do contexto do mercado de trabalho e da conjuntura económico-financeira do país, como da responsabilidade individual, passando por encontrar uma oportunidade que permita "mudar tudo" ou pela decisão mais radical de emigrar. Todavia generaliza-se a ideia de que a precariedade se vai normalizando nas lógicas de contratação e nas relações laborais e, desta forma, se interioriza na vida social destes jovens. Na verdade, estes vão tolerando as dimensões da precariedade no seu quotidiano e nas suas relações sociais.

Acho que vai ser complicada, acho que se calhar não vamos ganhar tão bem para já... ou nos primeiros tempos. E vais demorar mais tempo do que querias a ter aquela estabilidade financeira com o teu trabalho [...] [vês-te sempre em situações de incerteza contratual?] Sim... mas acho que isso já é um pouco do senso comum da nossa geração, já é o normal, já está um pouco interiorizado que vai ser assim. (Mariana, 24 anos, licenciada em Solicitadoria, com contrato a termo)

[...] depois claro eu também falava com outros colegas e amigos e o panorama no início da profissão era pior, eu era o privilegiado porque trabalhava numa empresa que fazia trabalhos comerciais [...] Todas as outras pessoas que eu conhecia trabalhavam em ateliers mais pequeninos, dez pessoas, cinco pessoas, estavam em situações ainda piores, a ganhar $500 €$ por mês... (João, 32 anos, licenciado em Arquitetura, a frequentar o doutoramento, a recibos verdes)

As expetativas sobre o futuro das carreiras profissionais viram-se ajustadas face à compreensão das dificuldades existentes no mercado de trabalho. E o que significa "estável" no emprego de hoje em dia? O que são para estes 
jovens os "bons empregos"? Trata-se, obviamente, de conceitos subjetivos, de acordo com determinados objetivos e ambições individuais. Existe, no entanto, o consenso de que um bom emprego será aquele que alie a satisfação em relação ao tipo de trabalho desenvolvido a um espaço para a realização pessoal; um contrato de trabalho que preveja alguma segurança; um rendimento justo e adequado face às necessidades do dia a dia; benefícios não financeiros (como um seguro de saúde); um ambiente de trabalho de respeito e valorização dos trabalhadores; e, por fim, verifica-se também a atribuição de importância à hipótese de conciliar de forma equilibrada o tempo de trabalho e da vida privada.

Os bons empregos são o caso da minha namorada que trabalha numa empresa de telecomunicações em que tem seguro de saúde, não é precária... quer dizer, tem um contrato de um ano, já é bom [riso]... tem um ordenado que chega aos $1000 €$, com descontos, chega aos $800 €$, digo eu - já é um bom ordenado para os dias que correm... (Manuel, 29 anos, mestrado em Geografia, com part-time em empresa de telecomunicações e ensino a recibos verdes)

Na próxima secção do texto procede-se a uma análise sobre o modo como a segmentação laboral e a perceção da permanência da incerteza decorrentes das situações de precariedade nas trajetórias profissionais dos jovens acabam por influenciar e interferir na sua esfera privada, no presente e futuro, bem como no alcance das transições de passagem para a vida ativa.

\section{A precariedade como um modo de vida: entre a semiautonomia e a incerteza do futuro imediato}

A precariedade é sobretudo associada à instabilidade contratual num dado trabalho ou atividade, gerando um sentimento de incerteza que ultrapassa a situação laboral e se estende por diversos setores e por outras esferas do quotidiano. Este dado, já estudado e demonstrado através de outros estudos (Alves et al., 2011), revela o impacto da precariedade na vida pessoal e social dos indivíduos, acabando por se transformar, desta maneira, num modo de vida. Ela atinge uma série de domínios que transcendem amplamente as relações de trabalho, embora, como veremos, a esfera laboral determine muitos dos aspetos mais alienantes que caracterizam a situação e a condição de precariedade.

\subsection{Rendimento, pluriatividade e semiautonomia}

A intermitência contratual significa, ao mesmo tempo, uma imprevisibilidade ao nível de remuneração. Contudo, apesar de variações, também 
neste aspeto tende a identificar-se uma constante: apesar de relativamente incerto, o rendimento obtido quase sempre é escasso e dificilmente cobre a amplitude das necessidades que os indivíduos consideram básicas (materiais ou outras). Deste modo, o rendimento nem sempre é suficiente para fazer face às despesas mais essenciais e prementes.

Para muitos dos jovens entrevistados, a obtenção de rendimento mais ou menos regular surge como uma das principais razões que levam à manutenção de uma situação de precariedade. Como se depreende, uma parte significativa destes trabalhos é mal paga. Os salários são baixos e raramente ultrapassam a quantia dos $800 €$ líquidos e, em muitos casos, encontram-se abaixo do valor do salário mínimo nacional. Mesmo assim, é muito habitual num horizonte de diversos meses um mesmo jovem trabalhador poder ser remunerado com quantias distintas, que podem variar em função do contrato ou do tipo de trabalho que no momento exerce.

Quando questionados sobre se o rendimento auferido era satisfatório para fazer face às despesas, a maioria dos jovens refere que o rendimento é suficiente apenas para cobrir as necessidades imediatas. A necessidade de que o rendimento que se aufere cubra as despesas como renda da casa, alimentação, estudos, em alguns casos cruza-se igualmente com a impossibilidade de poupar - aqui surge a ideia de que o dinheiro tem que "dar" para o momento, não havendo espaço para "extravagâncias", como investir em momentos de lazer, viajar; por vezes obrigando mesmo a retardar a compra de bens materiais necessários como livros, computadores, roupas ou transporte individual.

Com o baixo nível de rendimento que a maior parte destes jovens aufere é muito difícil usufruir de plena autonomia económica. Para compensar esta situação, torna-se necessário recorrer a outros recursos e ajudas. Uma via possível passa por acumular várias atividades em simultâneo. Por exemplo, para além do trabalho principal é sempre possível realizar biscates ou responder a solicitações para trabalhos esporádicos.

A pluriatividade torna-se um recurso importante na medida em que representa a diversificação das fontes de rendimento. No entanto, esta significa um esforço acrescido no qual o tempo de trabalho se prolonga pelo dia fora. Em alguns destes jovens a sensação de estar sempre a trabalhar é algo que também se torna constante e que resulta da sua condição precária.

Por seu lado, um dos fatores que justifica que os indivíduos aceitem trabalhos precários e mal pagos tem que ver com a necessidade de garantir algum rendimento regular que permita deter um mínimo de autonomia económico-financeira. Por este motivo, "estar precário" representa, na maior parte dos casos, encontrar-se relativamente dependente de outros. 
Na verdade, podemos considerar que se prolonga uma situação de "semiautonomia" em que o indivíduo parece nunca conseguir garantir uma completa autonomia financeira e material. É neste contexto que a família surge como o recurso fundamental nos vários tipos de apoio (sobretudo material). Esta continua a estar presente e a ser uma garantia por via do apoio financeiro, ou da oferta de vários tipos de bens, com maior ou menor regularidade. Neste sentido, do ponto de vista económico-financeiro, a precariedade representa uma situação de "semiautonomia" que se pode perpetuar ao longo de anos, independentemente de se viver ou não fora da casa dos pais.

Com que idade é que eu vou sair de casa? Se me fizerem agora um contrato quando o meu estágio do IEFP acabar eu hei de ficar a receber $800 €$ ou $900 €$, direi eu, teto máximo. [...] Quanto é que seria o salário normal, aceitável para uma pessoa sair de casa?! Eu direi que sem pelo menos 1000 ou $1200 €$ uma pessoa não consegue ir viver para Lisboa e pagar uma renda. [...] Para mim, estar até aos 28 anos em casa da minha mãe era uma ideia que até há quatro anos atrás era completamente absurda. (Sílvia, 23 anos, licenciada em Relações Públicas, estágio IEFP numa agência de publicidade)

[O rendimento que auferes dá para fazer face às despesas?] É, mas não sobra mais nada. Eu gostaria de comprar alguns livros (que não o faço), gostaria muito de comprar, sei lá, um chocolate qualquer (e também não o faço), roupa... [E para convívio, lazer?] Não, não há. [O dinheiro é para ajudar também em casa ou é especificamente para ti??] É para ajudar em casa e para fazer face às minhas próprias despesas. Os meus avós não me ajudam a mim diretamente, mas ajudam a minha mãe. Como ela está desempregada e não recebe subsídio, é só a pensão, os meus avós da reforma tiram parte para nós. Eles vivem no Algarve e nós em Lisboa. [Fazem transferências regulares?] Sim, sim. Todos os meses. (João, 25 anos, licenciado em História, a frequentar mestrado em Linguística, contrato a termo numa peixaria)

Esta situação social não resulta apenas da necessidade de assegurar diversos recursos materiais fundamentais para garantir o básico para uma vida aceitável; na verdade, esta corresponde a uma presença mais ampla na vida destes jovens que interfere com as mais variadas relações sociais que compõem o seu quotidiano. Neste sentido, a "semiautonomia" resulta também da situação de permanecer temporário numa dada ocupação laboral cuja remuneração não assegura as necessidades materiais (e outras) consideradas básicas. Estas são, ao mesmo tempo, percecionadas como algo que persiste e do qual não se consegue sair ou que não se consegue ultrapassar. 


\subsection{Futuro imediato: incerteza e adiamentos}

Para além do acesso aos recursos, a condição precária afeta profundamente as dimensões existenciais da vida social e individual, nomeadamente a dificuldade de projetar futuro, por mais imediato que seja. Este dado corrói a estabilidade e a segurança ontológica da vida pessoal e subjetiva dos indivíduos (Giddens, 1991). Como se tem demonstrado (Carmo et al., 2014), a precariedade afeta a forma como o tempo é vivido, promovendo uma constante fragmentação no decorrer do qual quase tudo se encontra a prazo, incluindo tanto o acesso a bens, serviços e equipamentos, como a própria estabilidade das relações sociais e afetivas.

No plano da projeção do futuro, ressalta enquanto preocupação fundamental conseguir alcançar uma relativa independência financeira e autonomia individual (como sair de casa dos pais, constituir família, comprar casa, etc.). Contudo, mesmo no caso dos jovens que já tinham uma certa independência financeira e se encontravam a viver sozinhos, persistia um certo receio de que a continuação da situação de precariedade significasse, por exemplo, voltar a casa dos pais/perda da sua autonomia. Esta hipótese é vista como um retrocesso que requeriria um ajuste de hábitos e dos estilos de vida adquiridos:

Tenho uma aversão muito grande a compromissos financeiros a longo prazo quando não tenho o mínimo de segurança. [...] Se eu deixo de ter dinheiro para pagar a minha parte da renda e das despesas, isso significa que eu tenho de sair de casa [...]. Estamos a falar do risco de uma desagregação completa da maneira como eu vivo. Estamos a falar de eu chegar aos 30 ou 31 anos e sei lá, voltar para casa da minha mãe porque já não tenho dinheiro. E não porque não tenha andado a trabalhar, porque o meu currículo está muito bem de saúde e cada vez cresce mais... isso não resulta é em proveito económico direto. (André, 29 anos, doutorado em Comunicação Social, investigador a recibos verdes)

Outro aspeto, referido nestes casos, é o adiamento da construção de projetos de vida em conjunto (e aqui já não é só uma questão de o próprio ter capacidade financeira para ser autónomo, mas também se o/a/s parceiro/a/s a têm ou não).

É uma incerteza muito grande, psicologicamente é... muitas vezes, diariamente, semanalmente, mensalmente, penso: "será que eu vou conseguir ter um filho?". Não sei! Quer dizer, aquilo que nós ganhamos mal dá para nós... eu nem sei se daqui a seis meses vão mandar-me embora ou não. E já tenho 27 anos... sou nova, mas quer dizer, a minha mãe teve-me com 25 , já tinha casa comprada, era enfermeira, o meu 
pai também estava empregado. (Mafalda, 27 anos, curso profissional em Assistente Dentária, radiologista, contrato a termo)

A reflexão sobre projetos de vida acabou por suscitar de forma natural um paralelismo com a vida da geração predecessora, nomeadamente, se esta viveria pior ou melhor que a geração atual. A perceção que os jovens entrevistados têm desta ideia depende, com base nesta amostra, daquilo que nos foi exposto como sendo o background socioeconómico dos progenitores. Numa primeira visão, esboçada sobretudo através da conversa com jovens provenientes de famílias menos favorecidas onde os pais também viveram situações de alguma vulnerabilidade económica e laboral, era comum relembrar que tal não seria verdade, uma vez que também estes tinham ultrapassado dificuldades e que, mesmo com as condições de trabalho atuais, se vive no presente com mais qualidade de vida do que na altura. Numa segunda visão, identificada principalmente junto de jovens provenientes de famílias mais favorecidas, encarava-se de forma mais cética o facto de os jovens de hoje em dia terem a possibilidade de viver melhor do que os seus pais, baseando-se acima de tudo na dificuldade em ter acesso a bens materiais, como comprar uma casa, e ter acesso a experiências de lazer, como ir de férias para o estrangeiro.

\section{Do bem-estar ameaçado às alternativas de futuro}

$\mathrm{Na}$ relação entre a dimensão mais objetiva relacionada com a insegurança profissional, e outra mais subjetiva, associada às consequências dessa incerteza na definição de vida e de futuro dos indivíduos, compreendeu-se que a precariedade acabava por ter efeitos na perspetiva que os jovens têm de si mesmo no seio da atividade laboral, o que, em alguns casos, acabou por afetar o seu bem-estar psicológico, nomeadamente criando problemas de ansiedade, stress e, em situações mais graves, mesmo depressão. A perda de qualidade de vida observa-se também na entrevista que aqui se inclui:

Eu lembro-me de ter uma visão muito clara do que é que iria acontecer no meu futuro, e apercebo-me de que é impossível perceber o que é que vai passar, eu não tenho a mínima ideia onde vou estar daqui a dez anos, não faço a mínima ideia, é completamente imprevisível e isso, para mim, assustou-me bastante. Comecei a sentir... epá eu nunca senti ansiedade antes do $3 .^{\circ}$ ano da licenciatura e comecei a ter muitos problemas de ansiedade clínica. E isto é uma coisa que mexe, sobretudo se és uma pessoa que pensa muito acerca do futuro e que gosta de planear as coisas. (Mónica, 22 anos, licenciada em Sociologia, mestre em Ciências da Educação, bolseira de investigação) 
As entrevistas realizadas permitiram concluir sobre o potencial efeito tentacular da precariedade, seja na dimensão profissional, seja na dimensão da vida privada e a conjugação das duas acaba por afluir em outra dimensão mais invisível: o impacto que toda essa incerteza acaba por ter no indivíduo (nomeadamente no seu bem-estar mental) e na forma como este se perspetiva enquanto membro da sociedade. $\mathrm{O}$ desgaste emocional e físico, identificado em muitos destes jovens resultantes da recursividade da entrada e saída de trabalhos e incerteza sobre o futuro, foi gerador de sentimentos de desintegração face àquilo que era esperado de si no mercado de trabalho, promovendo sentimentos de insegurança sobre si próprio e sobre as suas capacidades.

É um bocado desgastante, especialmente, ao final de um ano, às tantas aquele Excel que tinha referido, eu parei com o Excel, já estava a chegar às ' 380 candidaturas', e achava "vamos lá deixar isto que em vez de me estar a motivar, já me está é a desmotivar". Haverá algum problema como o meu CV? Depois há sempre aquela coisa de estares sempre a trabalhares o teu CV... ou há aqui algum problema... sei lá, com a minha cara?! É exatamente o quê? Não sei... Eu acho que é um problema de trabalho, há muita gente à procura de trabalho, basicamente é isso. (Fernando, 30 anos, licenciado em Engenharia Civil, explicador de matemática, sem contrato)

Por outro lado, face a esta desmotivação e tristeza perante a precarização das condições de mercado de trabalho parece surgir um aumento de preocupações de ordem social e coletiva: existe vontade de participar de forma mais proativa em sociedade, o que pode envolver uma panóplia de situações, desde uma lógica mais local (atividades de voluntariado, participação em coletividades de bairro que promovem a solidariedade entre vizinhos) à adesão a movimentos sociais e partidos políticos. De qualquer modo, as alternativas pensadas situam-se na maioria dos casos num plano sistémico, com referências a questões de justiça social que passam pela necessidade de uma maior redistribuição dos rendimentos e regulamentação do mercado de trabalho.

[Precariedade será para sempre?] Espero que não! Sabes o que é que eu acho que é preciso? É acabar com o trabalho, acho que a questão não é reformar o trabalho, mas repensar a própria ideia do trabalho [...] é preciso pensar em novas formas de organização, novas formas de vida, que não passem por esta centralidade de que o trabalho ocupa, há outras formas de viver! Nunca se trabalhou tanto como se trabalha hoje, nunca houve - e isto é paradoxal - nunca se trabalhou tanto e nunca houve 
tanto desempregado como há hoje. (Alice, 23 anos, licenciada em Sociologia, mestre em Ciências da Comunicação, estágio IEFP)

Há medidas de médio e curto prazo que podem ser implementadas e que passam por mais fiscalização, passam por leis, alterações profundas à lei do trabalho, alterações ao rendimento mínimo, etc. [...] Aquilo que se necessita de ser tentado é perceber como é que se consegue otimizar o sistema atual não para o lucro máximo, mas para o bem-estar máximo. (André, 29 anos, doutorado em Comunicação Social, investigador a recibos verdes)

Estes últimos testemunhos revelam uma capacidade crítica de projetar um horizonte futuro que ultrapassa o imediato e os constrangimentos presentes resultantes da condição precária. O primeiro aspeto a apreender destas posições é o de que a precariedade não tem de ser uma inevitabilidade que se normaliza na vida dos indivíduos e das organizações. Na verdade, convém referir que se trata em muitos casos de uma normalização relativamente tolerada enquanto prática nos procedimentos de contratação e na crescente desregulamentação dos direitos laborais, mas que não encontra respaldo no modo como os indivíduos vivenciam subjetivamente os efeitos da precariedade. Pelo contrário, o que se depreende do testemunho destes jovens é que a precariedade não é vivida como um estado normal, apesar de se estar a generalizar nos mais variados setores, empresas e instituições que constituem o designado mercado de trabalho. Ao invés, identifica-se um forte mal-estar resultante desta condição que, como vimos, interfere em várias dimensões da vida social e existencial do indivíduo. É perante esta sensação de mal-estar e de insatisfação profunda que surge a necessidade de perscrutar diferentes alternativas nas formas de organização social.

\section{Notas finais}

O objetivo fundamental deste artigo foi o de percorrer e caracterizar diversas dimensões (profissionais, socioeconómicas e existenciais) que marcam a vida dos jovens em situação laboral precária. O enfoque da análise deu primazia às componentes subjetivas e existenciais a partir das quais se percebe como a precariedade representa uma espécie de armadilha em que muitos destes jovens caíram e da qual temem não conseguir sair no futuro próximo. Esta sensação de recursividade gera uma forte angústia que, em alguns casos, compromete a qualidade de vida do indivíduo, tal como o seu bem-estar social e mental. É neste âmbito que se retoma a noção de precariedade como modo de vida, na medida em que esta afeta múltiplos setores e dimensões do quotidiano. 
A conjugação e o cruzamento dos diversos fatores identificados pode significar, a prazo, a emergência de uma espécie de crise existencial no seio da população trabalhadora mais jovem perante a qual o presente se torna, por um lado, crescentemente agreste, designadamente pela via de uma recorrente situação laboral pautada pela incerteza e pelo défice de reconhecimento profissional (da parte das entidades empregadoras e também dos colegas mais efetivos); e o futuro que, por outro lado, se perceciona como cada vez mais longínquo no sentido em que se torna difícil descortinar uma perspetiva de progressão profissional, assim como de melhoria e de autonomização económico-financeira das condições de vida. A vivência de um presente duro e adverso, conjugada com a perceção de um futuro indecifrável que foge ao controlo, representam ingredientes problemáticos e preocupantes que afetam profundamente a dimensão existencial e ontológica da vida destas pessoas.

Todavia, estes riscos crescentes terão efeitos que ultrapassam largamente a realidade específica de cada indivíduo. $\mathrm{Na}$ verdade, se nada for feito para inverter os processos caracterizados, estes afetarão profundamente (e, de certa forma, já estão a afetar) a sociedade em geral. A este respeito, os recentes estudos e análises que identificam os impactos do desemprego e da crescente precariedade laboral no mercado de trabalho em Portugal (Cantante, 2018; Caleiras e Caldas, 2017; OIT, 2018) levam-nos a alertar para as consequências que estas dinâmicas de precarização terão a prazo na sociedade em geral. Com efeito, todos iremos perder com a generalização e a suposta normalização da precariedade nas várias esferas e nos diversos contextos empresariais, organizativos e institucionais. Tal como referiu Pierre Bourdieu, "a precariedade inscreve-se num modo de dominação de tipo novo, baseado na instituição de um estado generalizado e permanente de insegurança visando coagir os trabalhadores à submissão, à aceitação da exploração" (1998: 118). Torna-se, por isso, fundamental equacionar políticas que permitam gerar espaços de reivindicação e de participação democrática que favoreçam a agência individual e coletiva e sejam capazes de produzir alternativas emancipatórias de organização social e laboral (Santos e Nunes, 2009). A este respeito a questão da capacitação da ação coletiva significa um pressuposto determinante para que a precariedade se desnaturalize e se transforme numa realidade estranha e cada vez menos normalizada.

Revisto por Rita Cabral 


\section{Referências bibliográficas}

Alves, Nuno de Almeida; Cantante, Frederico; Baptista, Inês; Carmo, Renato (2011), Jovens em transições precárias: trabalho, quotidiano e futuro. Lisboa: Editora Mundos Sociais.

Atkinson, Will (2013), "Class Habitus and Perception of the Future: Recession, Employment Insecurity and Temporality”, British Journal of Sociology, 64, 643-661.

Bartolini, Laura; Triandafyllidou, Anna; Gropas, Ruby (2015), "Escaping the Crisis and Emancipating Oneself: Highly Skilled Mobility from Southern Europe”, Altreitalie: Forum Europe and Migrations in the Third Millennium, 51, 36-52.

Beck, Ulrich; Beck-Gernsheim Elisabeth (2002), Individualization: Institutionalized Individualism and Its Social and Political Consequences. London: Sage.

Bourdieu, Pierre (1998), Contrafogos. Oeiras: Celta. Tradução de Miguel Serras Pereira. Bradley, Harriet; Devadason, Ranji (2008), "Fractured Transitions: Young Adult's Pathways into Contemporary Labour Markets”, Sociology, 42(1), 119-136.

Bove, Arianna; Murgia, Annalisa; Armano, Emiliana (2017), "Mapping Precariousness: Subjectivities and Resistance. An Introduction”, in Emilia Armando; Arianna Bove; Annalisa Murgia (orgs.), Mapping Precariousness, Labour Insecurity and Uncertain Liveliboods Subjectivities and Resistance. Abingdon: Routledge, 1-12.

Bynner, John (2005), "Rethinking the Youth Phase of the Life-Course: The Case of Emerging Adulthood”, Journal of Youth Studies, 8(4), 367-384.

Cairns, David; Growiec, Katarzyna; Alves, Nuno de Almeida (2014), “Another Missing Middle? The Marginalised Majority of Tertiary Educated Youth in Portugal during the Economic Crisis”, Journal of Youth Studies, 17(8), 1046-1060.

Caleiras, Jorge; Caldas, José Castro (2017), "Emprego e desemprego: o que mostram e o que escondem as estatísticas”, in Manuel Carvalho da Silva; Pedro Hespanha; José Castro Caldas (coords.), Trabalho e políticas de emprego: um retrocesso evitável. Coimbra: Actual, 197-243.

Cantante, Frederico (2018), O mercado de trabalho em Portugal e nos países europeus: estatísticas 2018. Lisboa: Observatório das Desigualdades. Consultado a 21.06.2017, em https://observatoriodasdesigualdade.files.wordpress.com/2018/04/o-mercadode-trabalho-em-portugal-e-nos-pac3 adses-europeus.pdf.

Carmo, Renato Miguel; Cantante, Frederico; Alves, Nuno de Almeida (2014), "Time Projections: Youth and Precarious Employment”, Time \& Society, 23(3), 337-357.

Carmo, Renato Miguel; Carvalho, Margarida; Cantante, Frederico (2015), "The Persistence of Class Inequality: The Portuguese Labour Force at the Turn of the Millennium”, Sociological Research Online, 20(4). DOI: 10.5153/sro.3810

Carmo, Renato Miguel do; Cantante, Frederico (2015), "Desigualdades, redistribuição e o impacto do desemprego: tendências recentes e efeitos da crise económico-financeira", Sociologia Problemas e Práticas, 77, 33-51.

Carmo, Renato Miguel do; Matias, Ana Rita (2019), Retratos da precariedade, quotidianos e aspirações dos trabalhadores jovens. Lisboa: Tinta da China. 
Comissão Europeia (2016), "First Results of the Implementation of the Youth Employment Initiative: Portugal”. Luxembourg: Publications Office of The European Union.

Costa, Hermes Augusto; Dias, Hugo; Soeiro, José (2014), “As greves e a austeridade em Portugal: olhares, expressões e recomposições”, Revista Crítica de Ciências Sociais, 103, 173-202. DOI: $10.4000 /$ rccs.5584

Estanque, Elísio (2014), "Rebeliões de classe média? Precariedade e movimentos sociais em Portugal e no Brasil (2011-2013)”, Revista Crítica de Ciências Sociais, 103, 53-80. DOI: $10.4000 /$ rccs. 5540

Ferreira, Vítor Sérgio; Lobo, Marina Costa; Rowland, Jussara; Sanches, Edalina Rodrigues (2017), Geração milénio? Um retrato social e político. Lisboa: Imprensa de Ciências Sociais.

Furlong, Andy; Cartmel, Fred (1997), Young People and Social Change: Individualization and Risk in Late Modernity (Sociology \& Social Change). Buckingham: Open University Press.

Gialis, Stelios; Leontidou, Lila (2016), “Antinomies of Flexibilization and Atypical Employment in Mediterranean Europe: Greek, Italian and Spanish Regions during the Crisis", European Urban and Regional Studies, 23(4), 716-733.

Giddens, Anthony (1991), Modernity and Self-Identity: Self and Society in the Late Modern Age. Oxford: Polity Press.

ILO (2015), Global Employment Trends for Youth 2015: Scaling up Investments in Decent Jobs for Youth. Geneva: International Labour Office.

Kesisoglou, Georgios; Figgou, Evangelia; Dikaiou, Maria (2015), “Constructing Work and Subjectivities in Precarious Conditions: Psycho-Discursive Practices in Young People's Interviews in Greece”, Journal of Social and Political Psychology, 4(1), 24-43.

Kretsos, Lefteris (2010), "The Persistent Pandemic of Precariousness: Young People at Work”, in Joerg Tremmel (org.), A Young Generation Under Pressure? The Financial Situation and the "Rush Hour" of the Cohorts 1970-1985 in a Generational Comparison. Heidelberg: Springer, 3-22.

Leccardi, Carmen (2005), "Facing Uncertainty: Temporality and Biographies in the New Century”, Young - Nordic Journal of Youth Research, 13(2), 123-146.

Leite, Jorge; Costa, Hermes Augusto; Silva, Manuel Carvalho da; Almeida, João Ramos (2013), “Austeridade, reformas laborais e desvalorização do trabalho", in Observatório sobre Crises e Alternativas (org.), A anatomia da crise: identificar os problemas para construir alternativas $\left(1{ }^{\circ}\right.$ relatório/preliminar). Coimbra/Lisboa: Observatório sobre Crises e Alternativas, 108-160.

McDonald, Paula; Pini, Barbara; Bailey, Janis (2011), "Young People's Aspirations for Education, Work, Family and Leisure”, Work, Employment and Society, 25(1), 68-84.

Mrozowicki, Adam (2016), "Normalisation of Precariousness? Biographical Experiences of Young Workers in the Flexible Forms of Employment in Poland", Przeglad Socjologii Jakosciowej, 12(2), 94-112. 
Nico, Magda (2014), “Life is Cross-Sectorial. Why Wouldn't Youth Policy Be?”, Youth Partnership. Strasbourg: European Commission and the Council of Europe.

OECD - Organisation for Economic Co-operation and Development (2016), Society at a Glance 2016: OECD Social Indicators. Paris: OECD Publications. Consultado a 07.02.2017, em http://www.oecd.org/social/society-at-a-glance-19991290.htm. OIT - Organização Internacional do Trabalho (2018), “Trabalho digno em Portugal 2008-18: da crise à recuperação". Genebra: Bureau Internacional do Trabalho.

Polanyi, Karl (1944), The Great Transformation: The Political and Economic Origins of Our Time. Boston: Beacon Press.

Pais, José Machado (1993), Culturas juvenis. Lisboa: Imprensa Nacional Casa da Moeda. O’Reilly, Jacqueline; Eichhorst, Werner; Gábos, András; Hadjivassiliou, Kari; Lain, David; Leschke, Janine; McGuinness, Seamus; Kureková, Lucia Mýtna; Nazio, Tiziana; Ortlieb, Renate; Russell, Helen; Villa, Paola (2015), "Five Characteristics of Youth Unemployment in Europe Flexibility, Education, Migration, Family Legacies, and EU Policy", Sage Open, 5(1), 1-19.

Santos, Boaventura de Sousa; Nunes, João Arriscado (2009), "Introduction: Democracy, Participation and Grassroots Movements in Contemporary Portugal", South European Society and Politics, 9(2), 1-15.

Simões, José Alberto (1999), "A televisão e as culturas juvenis: os media na construção social da juventude”, Fórum Sociológico, II(1-2), 161-179.

Sennett, Richard (1998), The Corrosion of Character. New York: W. W. Norton.

Standing, Guy (2011), The Precariat: The New Dangerous Class. London: Bloomsbury Academic.

Wright, Erik Olin (1997), Class Structure and Income Distribution. New York: Academic Press.

Artigo recebido a 15.07.2017

Aprovado para publicação a 26.10.2018

\section{Renato Miguel do Carmo}

Centro de Investigação de Estudos de Sociologia do Instituto Universitário de Lisboa Avenida das Forças Armadas, Edifício ISCTE, 1649-026 Lisboa, Portugal

Contacto: renato.carmo@iscte-iul.pt

ORCID: https://orcid.org/0000-0002-0052-4387

\section{Ana Rita Matias}

Centro de Investigação de Estudos de Sociologia do Instituto Universitário de Lisboa Avenida das Forças Armadas, Edifício ISCTE, 1649-026 Lisboa, Portugal

Contacto: artmatias@gmail.com

ORCID: https://orcid.org/0000-0002-4686-4926 


\section{The Existential Dimensions of Precariousness: Young Workers and Their Ways of Life}

Young people are considered to be the group most affected by the crisis, as they are more vulnerable to precarious working conditions. This article seeks to comprehend the social and individual impacts of precariousness on young people's way of life from the analysis of objective and subjective dimensions, which reflect an individual's perception of their own life trajectories in both the present and future. In-depth interviews were conducted with 24 Portuguese young adults with a university-level education. One of the main conclusions is that the future is becoming very unpredictable, which affects not only the vulnerable economic circumstances of young people but also their way of life. In fact, for most of those interviewed, the present labour experience incorporates some alienating aspects that puts constraints on the autonomy and the agency of the self.

Keywords: employment contract; job insecurity; labour market; living conditions; youth.

\section{Les dimensions existentielles de la précarité: les jeunes travailleurs et leur mode de vie}

Les jeunes sont l'un des groupes les plus touché par la crise, devenant ainsi plus vulnérables aux conditions précaires de travail. Cet article vise à comprendre les impacts sociaux et individuels de la précarité dans le mode de vie des jeunes, à partir de l'analyse d'un ensemble varié de dimensions objectives et subjectives, qui reflètent la perception des individus concernant leurs propres trajectoires aujourd'hui et à l'avenir. Des entretiens semi-directifs ont été effectués à 24 jeunes portugais diplômés. L'une des principales conclusions est que l'avenir est perçu comme très imprévisible et incertain, ce qui affecte non seulement leur situation économique, mais aussi leur façon de vivre. Pour la plupart des personnes interrogées l'actuel expérience de travail intègre certains aspects aliénants, qui restreignent la capacité d'autonomie et d'agence de la part du sujet.

Mots-clés: conditions de vie; contrat de travail; jeunesse; marché du travail; précarité de l'emploi. 
